\title{
Pesquisar junto aos mortos
}

\author{
VINCLANE DESPRET \\ UNIVERSITÉ DE LIĖGE, LIĖGE, BÉLGICA
}

TRADUÇत्AO ${ }^{12}$

IGOR ROLEMBERG

ÉCOLE DES HAUTES ÉTUDES EN SCIENCES SOCLALES (EHESS), PARIS, FRANÇA E MUSEU NACIONAL, UNIVERSIDADE FEDERAL DO RIO DE JANEIRO (UFRJ), RIO DE JANEIRO/RJ, BRASIL

HTTP://ORCID.ORG/OOOO-0002-5I7I-I254

\section{REVIS ÂO TÉCNICA}

\section{PAULO RENATO GUÉRIOS}

UNIVERSIDADE FEDERAL DO PARANÁ (UFPR), CURITIBA/PR, BRASIL

HTTPS://ORCID.ORG/0000-0002-8395-6272

“Os mortos são gente como os outros". Philippe, que, há alguns anos, é médium no círculo espírita da cidade onde moro, me brindou com essa proposição. Assisti a várias sessões desse grupo, em geral conduzidas por sua mãe, Michèle Willemsem, que também é médium. Essa reflexão, "os mortos são gente como os outros", foi concedida alguns meses atrás, durante uma entrevista, para a qual convidei os dois, em minha casa. No decorrer dessa longa conversa, pedi para eles me explicarem o modo como

\footnotetext{
1 [Nota do tradutor] Referência do artigo original: Despret, V. (2019). Enquêter auprès des morts. L’Homme, 230, 5-26. https://doi. org/10.4000/lhomme.33844. Ele é a versão aumentada da $2^{\text {a }}$ Conferência Lévi-Strauss de 2018, ministrada pela autora na École des Hautes Études en Sciences Sociales. Agradecemos a ela e ao comitê de redação da L'Homme, pelas autorizações gentilmente concedidas para a publicação desta tradução em português. Acrescentamos-lhe um resumo e mantivemos as palavras-chave da versão original. "Inquiries raised by the dead" foi o título em inglês que o artigo recebeu na tradução de Catherine V. Howard, publicada em: Despret, V. (2019). Inquiries raised bay the dead. Hau: Journal of Ethnographic Theory, 9(2), 236-248. http://dx.doi.org/10.1086/705734. Mantivemos este título nos metadados, porém elaboramos um outro abstract cujo conteúdo estivesse mais próximo ao do resumo em português, criado para a tradução publicada pela Campos: Revista de Antropologia.

2 [Nota do tradutor] O termo enquête, em francês, tanto nesse texto de Vinciane Despret, como em outros que trabalham a pragmática da linguagem, sustenta uma ambiguidade intencional entre "pesquisa" e "investigação", para simetrizar os diferentes modos de inquirição em que se lançam os atores, estejam eles inseridos no mundo acadêmico, ou não. Ao trabalho de campo universitário, como o de Despret, associamos geralmente o termo "pesquisa”, mas vale lembrar que a autora está particularmente interessada nos modos de inquirição ordinários, como os dos frequentadores de círculos espíritas, que, conforme sustenta, nada devem em termos de legitimidade epistemológica aos de fatura universitária. Assim, traduzimos "enquêter" no título por "pesquisar", mas em outros momentos optamos por "investigar", para ressaltar que essa ambigüidade está sempre presente, e desfazer dualismos. Portanto, quem pesquisa com os mortos? A filósofa, certamente, mas também as pessoas em contato com seus falecidos. As notas que se seguem, quando não precedidas por [Nota do tradutor], são todas da autora.
} 
entravam em comunicação com os defuntos: o que significa ouvir, cheirar, ou ver, nesse caso? Evocamos suas histórias, sobretudo a de Michèle, surpreendentemente comparável àquelas que os etnólogos interessados em destinos fora do comum descreveram, com provaçóes, exposições corporais perigosas, brigas com a morte, sentimentos de presença e surpreendentes sonhos premonitórios. Venturas que essas pessoas conseguiram socializar e souberam transformar em aventuras.

"Os mortos são gente como os outros", me dizia Philippe. Ao reler essa frase, lembrei que já havia encontrado formulações muito parecidas, ao longo de minhas pesquisas. Havia lido algo assim no editorial do New York Times de 24 de abril de 2014, intitulado "Neanderthals are People, Too". Seu autor, o geneticista sueco Svante Pääbo, diretor do Departamento de Antropologia Evolucionária do Instituto Max Planck em Leipzig, e responsável pelo projeto internacional de sequenciamento do genoma de Neandertal, opôs-se firmemente ao projeto de seu colega, George Church, de clonar um neandertalense. O que é mais impressionante é que o artigo começa evocando o avô do autor, morto de gripe espanhola, em 1919, com 30 anos de idade. Seus filhos e netos não puderam conhecê-lo, prossegue Pääbo. "Ele era um matemático brilhante", explica, e "como cientista, eu teria curiosidade em saber como ele era". "Mas", ele acrescenta ainda, "me consolo ao pensar que ele continua a viver em mim"3.

Vocês poderão notar que, quando tento me distanciar do tema, ele me toma novamente, de imediato. É o que acontece frequentemente com os mortos. Apontemos ainda - e isso não nos afastará muito do assunto - que a invocação do avô no argumento não é gratuita: “Desejaria”, escreve Pääbo em conclusão de seu artigo, "exumar os ossos de meu avô para recriar, a partir deles, um gêmeo monozigótico que viveria, assim, 95 anos após a morte de seu antecessor? A resposta é claramente não. E como minha resposta é não, por que seria diferente para o Neandertal?". Os mortos são gente também - em todo caso, se estamos tratando de mortos humanos.

Mas os não-humanos também podem ser objeto de requalificação e tornar-se gente. E foi novamente no New York Times que encontrei, ao acaso de minhas pesquisas sobre os animais, uma ilustração, mais precisamente no artigo de 5 de outubro de 2013, intitulado "Dogs are People, Too". Dessa vez era assinado por um especialista em neurologia, Gregory Berns. Berns descreve o trabalho de sua equipe com cachorros. Eles buscam saber o que os cachorros pensam, e talvez mesmo, destaca ele, o que eles pensam de nós, humanos. Como os cães não falam, os cientistas decidiram explorar o modo como seus cérebros funcionam através de uma técnica de imagem cerebral, a fim de estabelecer possíveis semelhanças. E eles descobriram que o funcionamento era muito similar ao dos humanos. Será isso que fará os cachorros serem gente como a gente? Na verdade, não creio que sejam as semelhanças cerebrais que determinem a possibilidade dessa aproximação, mas, antes de tudo, a maneira pela qual elas foram construídas. Quando similitudes são construídas em laboratório, aprendi que é preciso interessar-se pelo dispositivo que permitiu sua emergência. E, de fato, o dispositivo é muito impressionante: Gregory Berns e sua equipe organizaram formas de estágio para cães voluntários, ao longo das quais esses cachorros aprenderam a permanecer dentro do PET scan (supondo que o aparelho foi criado para eles). Quando digo “cães voluntários”, refiro-me a diversas características do procedimento experimental: os cientistas criaram um formulário de consentimento esclarecido, parecido com aquele

3 Todos os trechos de artigos de jornal ou de livros em inglês foram traduzidos por mim mesma. 
que os pais devem assinar no momento em que seus filhos participam de pesquisas. Nesse formulário, está indicado o fato de que a participação deve ser voluntária, e que o cão tem o direito de abandonar a experiência se o dono julgar que assim ele o deseja. E se o cão expressa, ele próprio, essa vontade, se ele não quiser entrar no aparelho, ou se ele manifestar vontade de sair, será dispensado da experiência. Os etnólogos Aude Michelet e Charles Stépanoff, num belo artigo, defenderam o argumento de que o antropomorfismo nos tornou humanos e que nossa capacidade de imputar motivaçóes, perspectivas e emoções a outras espécies teria, sem dúvida, influenciado o que chamamos de "sucesso evolutivo" de nossa espécie. Mas, observam, o antropomorfismo tem igualmente efeitos sobre o antropomorfizado: ao serem tratados pelos humanos como alter ego, "os cães acabaram por lhes serem parecidos" (Michelet \& Stépanoff, 2016:45). Note-se também que o antropomorfismo participa plenamente ainda do devir "pessoa" dentro da nossa espécie, pois é por tratarmos bebês e crianças como humanos entre humanos que esses últimos tornam-se pessoas como os outros, ou seja, diferentes como os outros. São práticas de engendramento, segundo Luc Boltanski, ou de instauração, se me refiro a Étienne Souriau.

Observo de passagem que esses três casos, o dos mortos familiarizados, o dos cães antropomorfizados e o do Neandertal re-humanizado, têm, como característica comum, mas também como diferença, o uso de tecnologias específicas. Acabo de descrevê-las para os cães, mostrando os efeitos do próprio dispositivo na construção da semelhança. Essa utilização tecnológica é clara hoje para o Neandertal, sobretudo a partir dos mais recentes trabalhos de arqueólogos e paleontólogos que, graças às técnicas de escavação e decifração, mas também graças às técnicas de sequenciamento do genoma aplicadas pela equipe de Pääbo, puderam recolocar em questão a imagem opaca, de bruto, que o Neandertal tinha, a qual - suspeito, junto com outros colegas - permitia ao excepcionalismo humano assegurar sua inquestionabilidade. As técnicas dos médiuns, por sua vez, são também tecnologias de redução da distância, já que elas, concretamente, ambicionam tornar [o morto] presente. São dispositivos de convocação. Mas isso não é tudo. E é sob o signo deste “isso não é tudo", que pontuava maravilhosamente os trabalhos de Lévi-Strauss, que gostaria de inscrever o que vem pela frente.

Mas isso não é tudo. Pois se trata de pôr em ata - ou em ato - que os mortos são gente como os outros, de reduzir a distância e construir formas de proximidade. E no entanto a proposição de Philippe sinaliza outra coisa. Se com esse "como os outros" ela insiste sobre a familiaridade das relaçóes com os mortos, ou seja, sobre o fato de que possamos ter relações com os mortos que apresentam o mesmo caráter de familiaridade daquelas que podemos ter com os vivos, ela indica, ao mesmo tempo, que os mortos são, assim como os vivos, diferentes uns dos outros. Prova disso é, por exemplo, o fato de Michèle relembrar, nas sessões em que as pessoas vêm para pedir para serem colocadas em contato com um falecido, "que nunca se sabe com quem podemos cruzar", retomando as mesmas palavras que o etnólogo Christophe Pons (2002) ouviu durante sua pesquisa na Islândia. Essa diferenciação se mostra, aliás, recíproca: somos pessoas também para os mortos, não apenas porque aqueles cuja presença é assegurada pelos médiuns se dirigem a pessoas específicas e bem identificadas (filho, filha, neto, neta, sobrinho, sobrinha, ou amigos), mas também porque, de forma notável, os mortos estão atentos à própria personalidade do médium. Assim, quando evocávamos os registros sensoriais pelos quais os médiuns recebem as mensagens, Philippe me confidenciou, com um certo humor: 
Pude constatar que os espíritos fizeram estudos de pedagogia. Sabemos que para dar uma aula, é preciso mobilizar todos os registros sensoriais que estão distribuídos entre os alunos (registros visuais, auditivos, sinestésicos...) e, assim, o professor tem de se movimentar, falar, escrever... No meu caso, eu tenho uma tendência auditiva, e é dessa forma que as mensagens me chegam em geral, enquanto as mensagens visuais são pobres para mim. Os espíritos se esforçam para fornecer a mensagem no registro sensitivo do médium para o qual se dirigem.

Observamos que o modo como Philippe formulou sua constatação apresenta uma característica familiar a todos aqueles que trabalharam com médiuns. Com efeito, há uma redistribuição da potência de agir, tendo, como corolário, um apagamento deliberado da pessoa do médium, seu retraimento: ele deve se deixar ser habitado por um outro ser e deve, para tanto, deixar que a vontade desse último substitua a sua. Esse apagamento é condição para o sucesso do dispositivo. Ele pode tomar diversas formas, identificadas tanto por Maurice Bloch (1993), quanto por Giordana Charuty (2002) ou Christine Bergé (1990). Mas todas essas formas manifestam que o médium é alheio a suas produções, é apenas um canal, o que ratifica a presença de um terceiro ali. Prova disso é, por exemplo, o fato de que às vezes o médium não compreende a mensagem que está transmitindo. Acrescento, de passagem, que esse modo de operar sempre coloca aquele que faz uma consulta numa posição de trabalho interpretativo, de pensamento, o que, a meu ver, vincula, então, esse dispositivo aos procedimentos terapêuticos. Voltarei a isso mais à frente.

Ainda assim, a não-compreensão da mensagem por quem a transmite atesta um estar-em-relação particularmente bem sucedido com o falecido. E ele será ainda mais bem sucedido, dizem os médiuns claramente, se a mensagem encontrar uma ancoragem no real. Pois é isso o que fará a mensagem: procurar uma ancoragem. E pôr aquele a quem ela se destina na busca dessa possível ancoragem, ou seja, em um trabalho de investigação: o que ela quer me dizer? o que ela quer de mim? Uma investigação com o morto. Em outros termos: a mensagem, à espera de significação, em busca de uma ancoragem, a mensagem como enigma, põe seu destinatário em movimento, coloca-o para pensar. Ela irá produzir um certo tipo de atenção e um outro regime de afeto - sobretudo se a mensagem não adquirir significado imediatamente. Em breve volto a isso. Parece-me que aí está uma dimensão terapêutica, essencial do dispositivo: não sua possível condição de sucesso, mas o possível sucesso em seus efeitos. Porém essa versão da história é a minha; para o médium, a questão do sucesso reside, antes, em sua possibilidade de ter constituído uma retransmissão confiável. "A mensagem", me diz Philippe, "nunca é tão convincente quanto nos momentos em que estamos tão surpresos quanto os outros: a mensagem toma, em certas ocasiões, caminhos tão tortuosos, que só receberá seu significado quando se realizar no real; é o real que lhe dá sentido, retroativamente". Philippe relata que ele estava transmitindo uma mensagem - prossegue ele, dizendo que é o mais frequente - cheia de banalidades: "Descanse", "Cuide-se". No entanto, ao final da mensagem, ele pergunta a um casal se há um problema com o carro. Diante da resposta negativa, ele lhes diz: "Tenho que transmitir. Não quero lhes preocupar, mas se houver algum problema, pensem nisso antes de dar partida”. Uma ou duas semanas mais tarde, o casal retorna para lhe agradecer: ele salvou a vida da esposa. Após a mensagem, fizeram uma revisão no carro e a esposa pegou a caminhonete para seus deslocamentos. Ora, seu veículo sofreu uma colisão violenta, sem con- 
sequências, dada a altura do assento do motorista. Num carro comum, em contrapartida, esse acidente teria conseqüências muito mais graves, e ela teria ficado no mínimo seriamente ferida. "Essa mensagem permitiu", diz Philippe, "por uma série de coincidências, se pensarmos que são coincidências, e a partir de uma mensagem banal, que as coisas tenham mudado".

Ao deixar em aberto a questão das coincidências, e decompondo um encadeamento, que, no final das contas, é bastante aleatório e suscetível de muitas outras reconstruções, Philippe traduz, na realidade, uma dimensão dessas situações sobre a qual, creio, não insistimos suficientemente: o fato de que elas não apenas são sempre marcadas por uma forte indeterminação, mas sobretudo uma indeterminação da qual o medium tem bastante consciência. E, ao reler as notas, me dou conta de que o dispositivo mediúnico estabelece uma ontologia, e uma epistemologia da relação entre verdade e real, de notável sofisticação: é o real que confere o sentido, ou seja, é o real que confere verdade ao anúncio. Em outros termos, é no real que o anúncio busca, e às vezes encontra, as condições de sua realização. Segundo William James, a verdade é aquilo que acontece com um enunciado; um enunciado em busca de verdade participa de uma realidade em processo de construção. E, nesse processo de se fazer a realidade, o portador do enunciado em busca da verdade tem contribuição ativa (1913 [1909]:69; 1948 [1911]:263). Não nos encontramos no regime da prova, longe disso, mas no da provação. Pois se trata mesmo de uma provação: um anúncio lança seu destinatário na busca de sua realização. Isso é próprio dos enigmas. Diante de um enigma, apenas uma resposta é possível para aqueles que sabem acolhê-lo: o que fazemos com isso? É a questão que eu mais ouvi nas histórias que me contaram as pessoas confrontadas com uma questão do defunto. E isso me parece indicar que elas haviam compreendido que o que tinham diante de si era da ordem do enigma.

O enigma do anúncio, tal como o concebe Philippe, preenche, assim, de forma admirável, as condições de felicidade que William James atribuía à verdade: na busca de se tornar verdadeiro, de se realizar, um enunciado faz sua contribuição para o real, sob o modo de uma ampliação. E, mais notável ainda, essa realização não equivale a uma resolução, pois a indeterminação que ele traz encontra-se, apesar de transformada, no desfecho de sua realização. Prova disso é a perplexidade que a acompanha: devemos chamar isso uma série de coincidências? $\mathrm{O}$ acidente teria acontecido se tivéssemos guardado o carro? A realidade empresta ao enunciado sua significação, e eu digo mesmo "empresta", porque essa última pode ser sempre submetida ao trabalho do pensamento, sem esgotar os múltiplos sentidos desse enunciado, nem o sentido de suas relações. "O próprio de uma indeterminação ativamente cultivada”, escreve Isabelle Stengers, "é de suscitar que outras indeterminações entrem em ressonância com outros modos de cultivo" (2007:44). Essa é a marca de todas a histórias que me foram contadas durante o tempo em que desenvolvia minha pesquisa, e daquelas que me chegaram depois do seu término, em resposta a ela.

O jovem etnológo Paul Sorrentino pesquisou, ao longo dos últimos anos, a invenção de um novo ritual de possessão no Vietnã. Pessoas aprendem, no quadro de um ritual, o àp vong, a acolher e deixar-se possuir pelo espírito de um de seus desaparecidos, permitindo a esse último expressar desejos que não foram realizados, de cuidar da família, de dar notícias, ou até - o que tem muito valor num país que esteve durante muito tempo em guerra, no qual uma grande quantidade de mortos não puderam ser 
encontrados - de os guiar na busca de seus corpos. Nas últimas linhas de agradecimento que abrem seu livro, Sorrentino afirma que certas passagens foram redigidas no quarto do hospital onde, cito, "[seu] pai se preparava a um combate que no fim das contas não teve tempo de levar adiante” (2018:11).

Durante nossa última conversa, eu lhe falei do depósito de meu manuscrito e do início do trabalho editorial, do qual esse livro é o resultado. Enquanto eu o escrevia, aprendi que podíamos tornar um morto presente ao simplesmente nos dirigirmos a ele. Então é isso: acabou. (ibid).

"Então é isso: acabou". Essas palavras, para além do fato de terem me emocionado muito mais do que poderei dizer neste momento, me redirecionaram às últimas linhas do epílogo do mesmo livro, quando, diante da multiplicidade de versões possíveis e contraditórias de uma mesma história, a da possessão de Kien pelo avô da esposa, Sorrentino conclui: "As pesquisas etnográficas, assim como as experiências de possessão, nunca se concluem realmente”. (Ibid:320).

Não acabou, porque jamais termina. Pois essa é mesmo a posição que Paul Sorrentino toma, quando confrontado à questão da verdade da possessão por um defunto - está-se realmente possuído? é realmente o morto? - a posição de aprender com aqueles que experenciam isso, a não encerrar a questão com uma resposta unívoca, mas, antes, a buscar uma ancoragem que corresponda melhor às experiências que deixam perplexos aqueles que se engajam nelas, uma ancoragem à altura de uma experiência que se encaixa ainda menos em categorias estreitas e binárias da crença, na medida em que transborda as da crítica, o tempo todo. Essa ancoragem, Sorrentino, com sabedoria, optará por exercê-la a partir das condições ecológicas que tornam essas experiências possíveis, a partir dos meios onde se alimentam para poder existir. Pois a questão da verdade pode constituir um verdadeiro veneno para essas situações, sobretudo quando - Isabelle Stengers nos ensinou - ela se põe nesses termos: "É realmente isso?” (2014:154).E, no entanto, ela não cessa de se colocar, frequentemente sob o modo - o que é uma bobagem nossa - do "ou...ou": ou você diz "realmente possuído", ou tudo isso é apenas um produto da sua subjetividade. O que é preciso aprender, e aí está a bela lição da ecologia das práticas que ela nos ensinou, é a procurar o regime pertinente no qual um enunciado, um ato, ou uma experiência, encontra o real, e torna-se verdadeiro. Conservar ainda mais inestimavelmente a questão da verdade, e cito novamente Paul Sorrentino, porque aqueles que se engajam nessa experiência da possessão "abordam-na tanto com discernimento e senso crítico quanto com emoções e expectativas construídas anteriormente a seus engajamentos no ritual de àp vong" (2018:33).

E é ao cultivo da hesitação e indeterminação, tão notáveis nessas situações, que o etnólogo é convidado. E, de fato, Sorrentino, ao longo da pesquisa, vai aprender a transformar a impossibilidade de saber "a palavra final da história" ${ }^{4}(\mathrm{Ibid}: 145)$ no que eu chamaria de uma "ética dos relatos". Amor fati.

Não buscar a palavra final da história. Acabo de mencionar, com relação a essa pesquisa no Vietnã, uma possível "ética dos relatos". Esse termo que seu trabalho me inspira, aplicarei hoje a esta interessante história que, ao que me parece, orienta a leitura do antropólogo Heonik Kwon acerca dos fantasmas no

4 [Nota do tradutor] Optamos pela tradução literal de "connaître le fin mot de l'histoire", porque a autora, em diversas passagens, destaca o inacabado, a impossibilidade da finititude e do conhecimento completo dos fenômenos experimentados. Mas em francês a expressão guarda também o sentido de "desvelar o segredo" - no caso em tela, a impossibilidade disso - e se adequa também ao que ela quer expressar. Agradeço ao revisor pela observação. 
Vietnã contemporâneo. Na região de Da Nang, narra ele, o hóspede de passagem recebe geralmente, ao fim da conversação, um copo d'água vindo do poço, que, segundo se diz, foi oferecido por um espírito. Esse primeiro copo d'água é ligeiramente salgado. Os seguintes, vindos do mesmo reservatório, não o serão. Nem todo mundo pode sentir o sal dessa água. Ora, Kwon fica intrigado: confessa ter conhecido a experiência do sal raras vezes (2008: 104). Como uma água de poço pode ter o sabor de água do mar? Por que para alguns e não para outros? É minha alma ou meu corpo, interroga-se Kwon, que reconhece o sal? E se alguém o reconhece e outros não, quem é que tem um problema? Ele ou os outros? Essas questões não pedem uma solução, mesmo que sempre possamos respondê-las. Aí está sua força performativa. Kwon leva isso em consideração, ao confessar que, para a questão de saber se o sal está na água ou na boca (para não dizer na cabeça), se é normal ou não prová-lo, anormal ou não fazê-lo - para a questão de como compreender esse fenômeno estranho - ele não tem nenhuma resposta razoável. "Mas", continua, "no lugar de respostas, a experiência do sal espiritual me conduziu a outros eventos e outras histórias, e minha sede de tornar-me capaz de sentir como os outros, abriu novos acessos para compreender esses eventos e essas histórias [...]. Um provérbio frequentemente evocado no Vietnã é: 'Os ancestrais comeram muito sal, os descendentes desejam água'” (Ibid:105).

Esse provérbio, que pode ser utilizado em contextos muito diferentes, pode ter vários significados. Um deles se liga a esta história:

Os verdadeiros desejos humanos, diz esse provérbio, não são aqueles de um indivíduo isolado. A origem do desejo encontra-se, como o sal da água ofertada pelo espírito, em outro alguém, e é somente na presença desse outro que a água se torna salgada. O desejo de se lembrar e comemorar pode, da mesma forma, ser um desejo que emerge entre um passado e um presente, e que é compartilhado entre aquele que lembra e aquele que é lembrado (Ibid:105-106).

São os mortos que reclamam a necessidade de serem lembrados? Somos nós que lhes imputamos esse desejo? Não dar a última palavra é respeitar o que Gilles Deleuze denominava um "agenciamento". É a relação de forças que sustenta um acontecimento; o desejo de ser lembrado e o desejo de lembrar "estão acoplados", juntos. Não há precedência. Desmembrar esse agenciamento, atribuir uma prioridade ontológica ao imaginário dos vivos - "ele seria a causa real desse desejo" -, ou à vontade dos mortos, retiraria todo seu significado, destruiria o que Étienne Souriau designou como seu "fulgor de realidade”, sua força ontológica própria, sua “maneira de ser” enquanto agenciamento (1939:10).

Se revisito hoje essa história que atesta uma ética dos relatos, é porque ela me parece traduzir não apenas um consentimento de não impor a palavra final da história, mas porque ela atesta também a vontade de transformar ativamente esse consentimento em uma obrigação: a de dar continuação. Uma obrigação de imaginar, de pensar, de honrar a recusa de a história se encerrar.

"Isso não é tudo". Ou, se tomo emprestado a Eduardo Viveiros de Castro a bela fórmula que ele oferece em retorno a Claude Lévi-Strauss: "Isso não é tudo, pois nada jamais é tudo" (2008:130). Isso não é tudo, porque Heonik Kwon aceita a provação do enigma, que não espera uma resolução, mas, ao contrário, uma continuação. Trata-se de reformular a questão para esta: o que faço com isso? Compreender não deveria querer dizer outra coisa, a não ser isto: "apre(e)nder com”. Dar continuação 
é isso, e retomo agora o que Mathieu Porte-Bonneville, inspirado em Wittgenstein, atribuiu ao termo "compreender"s: se eu pergunto a você sobre a relação entre dois, quatro, oito, dezesseis, você diz que compreendeu e propõe trinta e dois. Você dá continuação. Pois o que caracteriza os relatos que os mortos nos fazem criar é que, justamente, eles nunca terminam. Ao contrário, esses relatos são um protesto contra o que se dá por acabado. Ao que me parece, é o que se tira de todas as histórias que pude recolher, seja em sua forma, seja na continuação que elas suscitam. Há uma redistribuição constante de perspectivas e de potências de agir. São tecnologias de re-convocação. Os relatos, em outros termos, re-suscitam.

Com base nessa hipótese, me dei conta de que os relatos que havia transmitido, seja em publicações, ou em conferências que pude dar durante minha pesquisa, tinham o mesmo efeito. No início de 2015, minha pesquisa estava a princípio terminada, ou ao menos era esse o meu desejo; ia me voltar para outros viventes acompanhados de outros seres... por que não os pássaros? Os pássaros são muito interessantes também, e constituem outros modos bem promissores de comunicar a terra com os céus. Mas os mortos não entendem da mesma forma. Não apenas os mortos faziam com que os vivos fizessem coisas, e essa era o motivo de minha pesquisa, mas agora os mortos de uns faziam com que os vivos de outros fizessem coisas. Assim, bem na segunda semana de setembro, enquanto preparava esta conferência e retomava novas leituras descobertas posteriormente, recebi dois e-mails. Um de Bernard Féru que me dizia que, ao ler histórias que compartilhávamos, foi se dando conta de que o romance que havia escrito, La veuve du procureur (2018), seguia a intuição de várias pessoas, que se sentem compelidas a cumprir o que o morto não pode mais fazer. Um outro, de Christophe Laurens, me anunciava que ele havia perdido o pai no último verão. Continuava: "e pensei em você, quando fiquei escolhendo bons sapatos para ele passear no além”. Christophe me perguntava também se eu havia visto o documentário Carré $35^{6}$, relembrando-me que, num dado momento, vê-se um epitáfio que confia aos pássaros o cuidado de transmitir a uma menininha morta muito cedo os pensamentos dos vivos. Não me recordava dessa inscrição fúnebre, mas ela me fez lembrar um e-mail de Jean-Christophe Janin recebido no final de 2015, me contando que o casal com quem ele mantinha uma correspondência havia colocado, sobre o túmulo de sua jovem filha falecida, uma caixa de correios. Desde então recebem regularmente mensagens de pessoas que gostavam/gostam de Juliette e até mesmo de desconhecidos. Ele concluía dizendo que "ela ainda vive!". Acrescentou que sua mãe tinha afirmado: “É difícil criar uma criança morta”, e comentou: 'para tornar essa ação mais leve e positiva, seria melhor pensar em 'criar' como 'instaurar' e não como 'educar'”.

As palavras de Jean-Christophe são justas, "justas" no sentido de que tocam, com muito tato, a inteligência da experiência que ele transmite. Pois é exatamente como leitora de Souriau que também compreendia que o que fazem esses pais é "criar” uma criança, instaurar sua existência, promovê-la, e continuar a fazê-la crescer. Eles a preservam no seu ser. Essa nova existência, que prolonga aquela que Juliette havia começado, é exigente, demanda cuidados, inventividade e atenção, graças aos quais ela

5 Cf. o programa radiofônico "La grande table" sobre o tema "Precisamos elaborar nosso luto?", difundido na rádio France Culture, em 02 de dezembro de 2015.

6 Documentário autobiográfico de Éric Caravaca, realizado em 2017. Entre a França e o Marrocos, o ator-cineasta busca encontrar vestígios de sua irmã mais velha, Christina, morta aos três anos, de quem não resta mais quase nada, a não ser o "túmulo 35 ” do cemitério de Casablaca onde repousa. 
pode prosperar. Pois com essa caixa de correios, Juliette continua a viver para os outros, e, até mesmo, existir para outros que ela não conheceu em sua primeira vida, e que participam ativamente em sustentar a existência da qual ela se beneficia nesse momento. Ela recebe esse complemento de biografia que lhe permite estabelecer novas relações ou prolongar antigas, que lhe dá a possibilidade, em resumo, de estar presente (no sentido também de ser conjugada no presente) e de continuar a agir em outras vidas.

Mas o que esses gestos, e os relatos que os prolongam, fazem especificamente sentir, é a necessidade de manter viva e ativa a indeterminação. Eles encetam, para isso, todo um arsenal tecnológico a fim de preservá-la. Fazem, em outros termos, o que a psicóloga clínica Magali Molinié, inspirada por Deleuze, nomeia, para qualificar seu próprio procedimento junto aos enlutados, "acompanhar através do meio" (2006:137). Acompanhar através do meio, especifica ela, é abordar a questão de modo a não perder de vista nem os vivos nem os mortos; é aprender a acompanhá-los ou a encontrá-los por meio daquilo que os liga, que "os mantém juntos". É o que fazem os relatos: proteger a polifonia das versões. Pensar através do meio, o que fazem as pessoas que fabricam esses relatos, é também não separar aquilo que interrogamos - uma experiência, um ser, uma presença — do meio que ele/ela requer para existir. Esse tipo de relato constitui, nesse sentido, para nós, um dos nichos ecológicos privilegiados, não o único, mas um dos nichos possíveis. $\mathrm{O}$ arsenal tecnológico que reúne as condições de manutenção da existência é diverso. Há atos, que alimentam relatos, e que deles se alimentam: escolher com cuidado os calçados; preparar o prato preferido da esposa amada, no dia de seu aniversário; escrever cartas endereçadas ao ausente; dedicar uma obra, continuar o que ele ou ela fazia e que não pôde ser concluído; acolher as presenças; falar, sonhar, buscar os sinais e construir, a partir dessas experiências, e com muito cuidado, seus relatos. E para esses, como acabo de evocar, tratar-se-á, a cada vez, de uma pequena jóia de invenção linguística, de maneira a manter abertas todas as possibilidades, com, por exemplo, a engenhosidade da construção formal em termos de "como se", "como se ele quisesse me dar um sinal", particularmente capaz de sustentar a perplexidade que alimenta a experiência.

Assim, a expressão "como se ele quisesse me dar um sinal", que tantas vezes surge de uma forma ou de outra, deixa em aberto a questão da intenção do defunto, e intacta a incerteza de se o sinal é produto da interpretação daquele que o recebe, ou se emana “realmente" do defunto. É claro que há também o uso de metáforas, ou até mesmo a invenção de novos sentidos para as palavras. Existe, mais abertamente, a técnica de oscilar entre duas versões contraditórias: "É coisa da minha cabeça ou é outra coisa?". $\mathrm{O}$ relato, dessa forma, pela indeterminação que ativamente preserva, é mantido vivo. Pois, justamente, o perigo do qual escapa é a palavra final. É o que aprendi a chamar de "tato ontológico". É esse tato que encontro na resposta que dá o jovem Rachid à questão que uma de minhas estudantes de psicologia lhe faz, a saber, se ele às vezes sentia a presença de seu irmão mais novo, morto num acidente de moto:

Sim, muitas vezes, por uma sombra, um barulho, pelo sonho. Pelos objetos que pertenciam a ele também. Assim que sinto sua presença, aceito a princípio essa presença e tento deixar as portas e janelas abertas, ou até mesmo abro as cortinas para deixar a luz penetrar. Não tenho medo ou coisas do tipo. Permaneço mais passivo e tento lidar com isso. Quando sinto sua presença, abro a janela para que ele possa sair se quiser. (Doutrelpont, 2012). 
Sentimos nessa narração uma gradação habilmente orquestrada, da distribuição daquilo que se chama "agentividade" ou "agência”, e que traduzo, seguindo Bruno Latour, como potência de agir: sombras, barulho, sonho, objetos que pertencem ao defunto e que apenas evocam a presença; depois a luz e as janelas abertas que preparam não mais a evocação, mas a invocação; por fim, a janela aberta para deixa-lo partir, se assim o quiser, atesta, com notável tato, um ritual de convocação surpreendentemente sofisticado. Rachid cria a situação que permitirá a esse desejo existir, e esse desejo ganha ainda mais autonomia, porque ele pode se manifestar como desejo de não dar continuidade à convocação, ou, mais precisamente, decliná-la.

Mas restava uma modalidade que não havia levado em conta durante minha pesquisa, ou que me havia estranhamente escapado: prolongar o relato pelo meio mais simples: abri-lo aos outros, mas desta vez sob o modo da ficção. E oferecer, através dela, o suplemento biográfico que o morto parece pedir. Uma senhora me enviou um e-mail durante o verão de 2016, e eis o que ela conta:

Minha mãe, Lore, faleceu há mais de um ano, no dia 7 de maio de 2015. Enquanto era viva, expressou a vontade de ser cremada, ao contrário de meu pai, enterrado 17 anos antes. Grande viajante, tendo trabalhado na aviação civil de 1958 a 1970, apaixonada pelos desertos, mamãe havia expressado, várias vezes no passado, o desejo de que suas cinzas fossem dispersadas no deserto. Em nossas últimas conversas, tinha compreendido que o deserto que idealmente poderia acolhê-la seria o de Namíbia. Seria então esse, sem que ela tivesse, aliás, nitidamente (linda expressão) pedido. O deserto de Namíbia e sua areia alaranjada a marcaram, pois foi o último que havia descoberto antes do nascimento de seu único neto; o deserto mais velho do mundo, "o mais especial" segundo suas próprias palavras. Para não falar das diversas ligações com esse país, antiga colônia alemã, que só podiam atrair sua personalidade ambivalente e desenraízada, tendo mamãe nascido na Alemanha e depois migrado para França. Para mim, no ano passado, isso ficou muito claro. Sua destinação final tinha que ser essa, eu (me) devia atender a esse pedido implícito, e essa seria sua última viagem. E através dela, mamãe me faria descobrir outros horizontes, uma outra perspectiva... para assegurar um mensageiro, questão de transmissão. Ao longo do verão de 2015, dei início aos procedimentos para visitar com nossos familiares (meu filho e meu companheiro) a Namíbia e leva-lá para lá. Seria mais correto dizer que me engajei numa verdadeira corrida de obstáculos. Efetuei e cumpri todas as formalidades requeridas, mais até do que seria preciso, tendo obtido todas as autorizações necessárias para que o translado da urna funerária ocorresse sem transtorno. Depois aguardei a data de partida. Essa foi uma longa espera; investi muitos e grandes afetos nessa viagem. Já em Namíbia, por fim (the end? ainda não), perdemos, no segundo dia de nossa estada, uma parte de nossas bagagens, roubadas de nosso veículo. Nossas malas estavam no bagageiro do carro alugado, trancado e estacionado na cidade. Entre as sacolas roubadas estava... a urna contendo as cinzas de mamãe! No dia 07 de junho de 2016, ou seja 13 meses depois, dias após dia, de ela ter dado seu último suspiro. Ela literalmente partiu pelos ares, mas não no sentido que eu previa. Para quem? Para ela? Para mim? Passado o choque e o desmoronamento emocional ocasionado por essa desventura surrealista, procuro a partir de agora qual sentido dar a essa história. Esse relato pode parecer rocambolesco, digno de um roteiro de filme. Mas não é nada disso. Ele toca em algo essencial e profundo. Eu percebo isso, mesmo se não consigo ainda ter o recuo necessário em relação ao acontecimento. Tenho, é claro, algumas pistas de reflexão, algumas convicções e 
intuições, mas enfrento às vezes alguns sobressaltos, angústia intensa, quando recordo o roubo. Fiz boletim de ocorrência no local, mas a polícia namibiense não encontrou nada até hoje, mesmo que o agente de viagem tenha, até onde sei, lançado comunicados na rádio e nas redes sociais. Devo, agora, prevenir o Quai d'Orsay, caso a urna seja encontrada no futuro, por causa da legislação relativa à proteção dos corpos! De fato, me senti desprovida; minha ação ficou inacabada, não conduzi esse projeto íntimo e pessoal até o fim... Mamãe aterrissou no solo da Namíbia mas onde estão suas cinzas hoje? [...] Após ter deixado a Namíbia com alguns pesares (um eufemismo), me pergunto: teria desnaturado a vontade de mamãe ou, pelo contrário, ela se escapuliu para ganhar definitivamente uma forma de liberdade? No final da vida, ela havia se definido como um 'pássaro migratório’... Estaria ela me convidando a desapegar disso?

Confesso que achei a ideia de uma fuga tão bonita que respondi ao e-mail nesse sentido. O que qualifiquei de "magnífica escapadela póstuma" me pareceu ao mesmo tempo, dentro da idéia de minha interlocutora de um convite a desapegar disso, uma lição de liberdade. Os últimos desejos, muitas vezes esquecemos, exigem uma continuação. Esse é um dos sentidos possíveis ao que chamamos de "herdar" - aliás, deveríamos falar mais em "penúltimos desejos", estando os vivos encarregados de cuidar dos últimos. Minha interlocutora me respondeu pouco tempo depois de ter se matriculado em uma oficina de escrita, dizendo estar preparada desta vez para dar essa continuação sob o modo da ficção, e oferecer a sua mãe o que Souriau consideraria talvez como uma promoção dentro da existência. O roubo não teria a palavra final.

A história de Lore, morta viajante, poderia encontrar ressonância com a belíssima pesquisa realizada por Arnaud Esquerre (2011) sobre a circulação das cinzas. Na verdade, graças ao roubo, as cinzas de Lore beneficiaram de muito mais liberdade do que autoriza a lei francesa desde 2008 as dificuldades administrativas da viagem e a necessidade de prevenir o Quai d'Orsay são provas dessas restrições de liberdade. Dez anos antes, minha interlocutora teria escapado de todos esses aborrecimentos administrativos. Com efeito, entre 1976 e 2008, explica Esquerre, com a generalização da cremação e a relativa ausência de enquadramento legislativo, milhares de mortos circularam livremente pelo território, entre a população, o que, aliás, levou Grégory Delaplace (2015) a destacar que o lugar dos mortos se punha menos em termos de lugares do que de trajetórias. Porém, mais surpreendente ainda, ao ler a pesquisa de Arnaud Esquerre, é o estranho complexo de pensamentos que regeu a mudança da lei. Gostaria de me ater a dois dos argumentos que foram apresentados. Para introduzir o primeiro, retorno por alguns instantes à comparação que abria minha apresentação, relativa a todos esses seres problemáticos que são chamados a serem gente como os outros. Por falta de tempo, deixarei os cães de lado para evocar novamente o Neandertal que Svante Pääbo queria proteger de uma tentativa de clonagem. No final de sua argumentação, Pääbo recorre tanto a seu avô quanto ao Neandertal, e termina por essa frase: "Que descansem em paz". E esta é uma reclamação recorrente, que podemos encontrar, por exemplo, no final da Primeira Guerra Mundial, como sublinha o historiador Jay Winter, quando os políticos, em seus discursos, invocavam os mortos para restaurar a ordem social, fazendo-os reféns de conflitos que lhes eram completamente estranhos. Isso despertará a indignação de muitos soldados, incluindo o poeta Marc de Larreguy, que pedirá, em nome de seus camaradas - aos quais, se juntará 
pouco tempo depois, com sua morte - "que os deixemos enfim apodrecer tranquilamente" (apud Winter, 2008 [1995]:229). Não deveríamos deixar os mortos tranquilos, para retomar o título de um artigo de Pascal Boyer (2016), distorcendo-o um pouco? Ou ainda, na versão espontânea de Emmanuel Berl, "se cremos que os mortos sobrevivem, como acreditar que eles não fazem nada, que não tem nada a fazer, que não os incomodamos nunca?” (1995 [1956]:80). Voltemos à pesquisa de Arnaud Esquerre: o argumento da tranquilidade dos mortos, surpreendente nesse início do século XXI, parece poder nos convencer da necessidade de uma regulamentação sobre sua circulação. Acabou a festa. Ou, para resgatar uma das formulações utilizadas por um relator da Assembléia Nacional, "o princípio da paz dos mortos impõe [...] que a sepultura escolhida seja estável” (apud Esquerre, 2011:79). A questão jurídica, na verdade, é identificar os lugares onde repousam os mortos, imobilizá-los e torná-los acessíveis a todos. Um segundo argumento intervém aqui, associado, de forma estranha, ao primeiro, pois vem das profundezas da doxa psicológica e se assemelha ao que poderíamos chamar de "novo regime das obrigações do luto". Com efeito, uma eventual apropriação das cinzas, ou sua disparição, ameaça, segundo o legislador (e segundo vários atores que se posicionaram nesse caso, inclusive representantes da Igreja), a possibilidade para os enlutados de fazerem o trabalho de luto. E podemos concluir, tanto com Arnaud Esquerre quanto com a socióloga Dominique Memmi (2014), que o que estava em questão era a proteção do psiquismo dos vivos.

Não voltarei ao que o psicanalista Jean Allouch (1997), a psicóloga Magali Mouliné e alguns outros denunciaram como o absurdo desse trabalho de luto, que não deixa de evocar uma enésima tentativa de domesticação das psiques. A aparente incongruência que consiste em conceder aos mortos uma vontade, a de estar em paz, e, ao mesmo tempo, invocar um sistema teórico que afirma que quando os mortos morrem eles estão mortos, e portanto não devem desejar mais nada, talvez não seja tão incongruente assim, se pensarmos que essas duas injunções, no fim das contas, convocam uma mesma atitude: a de querer claramente manter a separação entre vivos e mortos. Se deixá-los em paz significa deixá-los serem/estarem mortos, e se o trabalho de luto, como prescrição, implica uma imposição de se separar deles, os argumentos relacionam-se a uma mesma regra de socialidade, tanto para os mortos como para os vivos. Isso me parece ainda mais plausível diante do fato de que - dado o uso da teoria do luto pelo Estado, por sua vontade de retomar por conta própria a imposição de separação [entre vivos e mortos], para proteger o psiquismo de seus cidadãos - um dos argumentos a favor de tornar disponíveis a todos as cinzas do defunto repisou uma série de anedotas infelizes, por exemplo o fato de que a detenção em domicílio da urna com as cinzas de uma primeira esposa teria ocasionado o pedido de divórcio da segunda, ou ainda, a obrigação, para uma criança, de saudar todas as manhas seu irmãozinho falecido.

Seria de se esperar que para os círculos espíritas, cujas práticas vão totalmente em sentido contrário à teoria do luto, a questão da tranquilidade dos mortos não fosse levantada, pois, longe de favorecer a separação, suas práticas não cessam de gerar contatos. Ora, uma análise das sessões me parece, ao contrário, mostrar uma clara preocupação dos médiuns com o fato de que os vivos podem, por vezes, atrapalhar o destino de seus familiares falecidos. Vale ressaltar que essas sessões, pelo menos no círculo que frequentei regularmente para minha pesquisa, são coletivas, organizadas duas vezes por semana numa 
sala que acomoda geralmente cerca de trinta pessoas. Ao entrar, os participantes podem, se desejarem, deixar uma fotografia do defunto com o qual gostariam de entrar em contato, e que será entregue aos dois médiuns oficiantes. Isso não impede visitas intempestivas de mortos não convocados por uma fotografia. Na verdade é o que mais acontece, seja para os mais acostumados, que acabam por conhecer bem os médiuns, seja para as pessoas de passagem. Gostaria de evocar duas situações, mas muitas outras poderiam receber esta mesma leitura, onde ficou claro para mim que o trabalho de Michèle e de Philippe consistia em desfazer laços muito apertados ou mal tecidos, em nome do bem-estar dos mortos. Michèle se dirige a um homem com aproximadamente 40 anos, em tom de reprovação. Sua esposa está aqui, diz ela. Ela não está bem. "Parece que você se compraz com a infelicidade”. Ele exclama: "Me comprazer com a infelicidade! Só faltava essa!". Todo mundo ri. Michèle continua: "Mas você deixa sua mulher infeliz; sua esposa se sente culpada. Não podemos culpabilizar os mortos. Não é culpa deles terem ido embora; era a hora deles, não há nada que possamos fazer. E sua mulher se sente culpada porque você a deixa culpada”. Manifesta-se nessa troca uma inflexão sutil na teoria do luto. E essa inflexão inverte radicalmente a relação. Não se trata mais de se desligar do falecido para reinvestir outros objetos, "liberar-se das amarras", como dizem alguns. Não. É a morta que, aqui, pede para ser liberada. Se, com essa inversão, parece que o destino do morto está no centro de preocupações dos médiuns, não deixaremos de notar, entretanto, que o que está em jogo também aqui, e que a médium desfaz, é a impossibilidade para um vivo de tomar a difícil decisão, às vezes impossível, de enviar o morto a uma forma de não-existência ao se desfazer de uma dor que atesta o fato de que o morto existiu, uma dor que mantinha [o morto] no ser. Aí está a genialidade do dispositivo: se a ordem vem da própria morta, se a obrigação de se reconectar com a vida emana dela como uma necessidade, isso pode ser atendido. É o que me leva a dizer, ou a redizer, que o dispositivo espírita é um dispositivo terapêutico. A outra situação diz respeito a um jovem que veio com a fotografia de seu amigo. Ele havia se matado alguns meses antes. Com bastante tato, Philippe lhe disse que não poderia entrar em contato com ele, porque estava muito mal, e que eram outros seres que lhe respondiam. Continuou:

Falam-me de alguém que era muito otimista, com uma visão um pouco ingênua, mas progressivamente aconteceu alguma coisa, ele foi de desilusão em desilusão, e não havia mais nada de interessante ou bonito. Enquanto era vivo, teve que se isolar. Você se lembra dele quando ainda estava bem? [o jovem responde que sim]. Se você pensar nele enquanto ele ainda estava bem, isso poderia ajudá-lo a partir. É como se ele estivesse num casulo trancado, é o que me dizem outras entidades. Era uma pessoa muito gentil, super sensível. Ele esperava que o mundo fosse como ele. São realmente desilusões que aconteceram progressivamente. Não é nem mesmo uma questão de culpa, ele ainda não está neste ponto. Quando pensamos nele, pensamos no fim e isso o prende ainda mais. Isso lhe demanda um processo ativo de vê-lo feliz e sorridente. É necessário e útil enviar-lhe [ao morto] pensamentos positivos e visualizá-lo feliz e alegre. Se você foi instado a trazer a foto dele, é porque há algo a se fazer por ele. Será preciso retornar com sua foto daqui a algum tempo.

A descrição do vidente está correta (eu conhecia tanto o jovem como o seu amigo), ou ainda - deixemos de lado o que sabemos e que nos situaria num regime de verdade que talvez não seja o 
mais adequado nesse enquadramento - ela toca de modo correto. Pois a questão não é de saber se ele diz ou não a verdade. A questão é de compreender o que sua proposição toca, e quais são seus efeitos. Ela faz sentido; ela se torna verdadeira; ela reconstrói a história de tal modo que oferece algo em que se apegar [uma ancoragem]. O que não pôde ser feito ainda o pode ser. Essa proposição põe o jovem enlutado numa outra postura em relação ao falecido; ela transforma sobretudo, com um mesmo gesto, o regime de ação e de afetos: o faz passar de um regime passivo a um regime de atividade, de paixões tristes a paixões alegres. $\mathrm{O}$ vivo, assim ativado e tocado, parte com uma responsabilidade: reconstruir o passado, ativamente, para abrir outros possíveis no futuro. Agir e transformar as maneiras de ser, não retrospectivamente, mas retroativamente.

A ancoragem que escolhi certamente não seria aquela pela qual os videntes descreveriam suas práticas, o que obviamente levanta a questão da fidelidade e da interpretação. Paul Sorrentino encontrou um problema relativamente similar com os pesquisadores vietnamitas trabalhando no Centro de Pesquisa sobre os Potenciais Humanos, em Hanoï. Eles se esforçam em mostrar a veracidade das competências que a possessão emprega. Apesar de compartilharem o interesse pela possessão, Sorrentino observa que esses pesquisadores são mais relutantes em aceitar sua ideia de que as próprias atividades de pesquisa teriam contribuído ao desenvolvimento das práticas de possessão pelos mortos (2018:155, nota 19). É completamente compreensível que eles tenham o sentimento de que essa leitura construtivista possa ir de encontro ao regime da prova que guia seus trabalhos, pois esse regime de prova exige a autenticidade dos mecanismos de possessão, uma autenticidade que se veria irremediavelmente manchada de suspeição, se viéssemos a acreditar que as pesquisas poderiam ser a causa do fenômeno que eles estudam e que os pesquisadores o promovem a partir do momento em que decidem estudá-lo. Mas Sorrentino não pode aderir a esse regime da prova, pois isso o obrigaria a aceitar uma definição cienticista da verdade: só existe realmente o que existe por si próprio. A abordagem construtivista que ele escolhe, aceitando que o trabalho de pesquisa é parte constitutiva do fenômeno que os pesquisadores observam, permite-lhe não ter que sentenciar sobre o conteúdo exato da realidade que ele estuda, e escapar da escolha intimatória entre "é construído" e "é real". Não. Como Bruno Latour nos ensinou, uma vez que nos livramos da definição cienticista das ciências, o fenômeno é tão mais real quanto mais bem construído. Ao pesquisador cabe estudar como é construído, e sobretudo, como isso se mantém. Mas o problema da verdade ou da autenticidade não é um problema abstrato para esses pesquisadores vietnamitas: esse centro de pesquisas teve de enfrentar inúmeras dificuldades para obter do Estado a possibilidade de desenvolver seus trabalhos, obter um amparo legal e não cair sob ação das leis contra as superstições (Sorrentino, 2018:157). Como, ao mesmo tempo, não colocar os pesquisadores em perigo sem deixar de atender aos requisitos de sua própria prática? É aí que o pesquisador se encontra, sem dúvida, na posição do diplomata que põe em cena Isabelle Stengers $(2003,2006)$ : trata-se de aprender a pensar com os outros, mas sabendo que será preciso retornar aos seus. Estamos longe aqui da palavra final.

Fiquem tranquilos, no que concerne esta conferência, estamos quase lá [no fim]. Mas eu seria negligente, voltando para Michèle e Philippe, se, ao tratar de pensar a dificuldade de compreender o trabalho dos médiuns como um trabalho terapêutico, não recorresse ao auxílio extraordinário que constitui, para vários dentre nós, o trabalho de Jeanne Favret-Saada. O antropólogo Jérémy Damian 
(2014:528) relata que, quando ela retorna, algumas décadas mais tarde, ao dispositivo de desenfeitiçamento que havia estudado no Bocage, optando por apresentá-lo como um "dispositivo terapêutico" de cura e os desenfeitiçadores como "terapeutas", ela supõe que:

a acolhida de uma tal proposição não se fará no sentido que teria parecido mais óbvio: os desenfeitiçadores sentindo-se realizados por serem enfim reconhecidos como verdadeiros e eficazes terapeutas. Ela especifica, com efeito, que os 'verdadeiros' terapeutas - aqueles que têm o habito de se apresentar enquanto tais - estariam, no fim das contas, mais inclinados a aceitar os desenfeitiçadores como um dos seus, do que os desenfeitiçadores estariam para se reconhecerem como pertencentes ao círculo dos terapeutas (Ibid: 529).

Jérémy Damian retomou o problema em seu próprio campo com praticantes da danse improvisation contact e demonstra que o que poderia ser vivido como uma traição pelos desenfeitiçadores mostra-se, e aqui são meus termos, um compromisso justo. Pois, de fato, Jeanne Favret-Saada opta por deliberadamente não operar o gesto crítico que consistiria em bifurcar o real entre, de um lado, aparências, ilusões, subjetividade ou projeções, e, de outro, uma realidade verdadeira à qual apenas o pesquisador crítico teria acesso. Assim como ela não remete, a não ser excepcionalmente, a uma interpretação simbólica da feitiçaria - o que seria a alternativa "aceitável” para a vulgata antropológica - ela constata, aliás, que a referência ao simbólico é geralmente mais convocada nos momentos em que o observador se encontra confrontado com enunciados que considera falsos (2009:149). Ela oferece, assim, a seu campo uma abordagem pragmática em termos do que "faz" o desenfeitiçamento e o que ele permite as pessoas fazerem. Se lhe parece interessante autorizar-se a não ter a mesma grade de leitura dos desenfeitiçadores, escreve Jérémy Damian, "é que isso lhe permite descolar-se da alternativa que mantém refém a eficácia dessas práticas entre "acreditar" ou "não acreditar". Sem emitir nenhum julgamento, sem descreditar nenhuma experiência, ela "povoa o mundo com uma prática suplementar interessante" (2014:529). E Damian relembra o que Viveiros de Castro atribuía como tarefa da antropologia: "Se há alguma coisa que cabe de direito à antropologia, não é a tarefa de explicar o mundo de outrem, mas a de multiplicar nosso mundo" (2009:169).

A questão da divergência se coloca para mim de outro modo ainda, pois, no fim das contas, minha ancoragem prático-teórica é muito mais próxima da dos médiuns do que da prática de desenfeitiçamento das terapias convencionais. Philippe e Michèle sabem que, ajudando os mortos, ajudam os vivos. E sabem que é preciso ajudar os vivos a cuidar dos mortos. A leitura que proponho a eles é, na verdade, muito semelhante, em aparência, à deles, exceto que a minha inverte radicalmente a perspectiva. Ela desloca o foco dos mortos para os vivos, não para negar a possível implicação dos mortos, mas porque tenho que admitir que meu saber se interrompe aí. Não posso saber se eles ajudam os mortos, nem se esses últimos são afetados por essas histórias. Mas eu posso ver e ser sensível ao fato de que as proposições dos médiuns não apenas ajudam os que ficam- o que não é pouco - como são também apaixonantes. E que o mundo que eles contribuem a fazer existir, e no qual eles trabalham, é bem povoado. Eduardo Viveiros de Castro dizia ainda que a antropologia estuda as variações impor-

7 Em particular os capítulos II, “Terapia sem saber”, e III, “A invenção de uma terapia” (Favret-Saada, 2009: 24-77) 
tantes. Michèle e Philippe conferem importância a mais seres para os quais os vivos importam. Não é tudo. Mas já é muito importante.

Vinciane Despret é professora do Departamento de Filosofia da Université de Liège, na Bélgica.

\section{Tradução}

Igor Rolemberg é doutorando em Ciências Sociais na École des Hautes Études en Sciences Sociales (EHESS) em co-tutela com o Programa de Pós-Graduação em Antropologia Social do Museu Nacional, Universidade Federal do Rio de Janeiro (UFRJ).

\section{Revisão técnica}

Paulo Renato Guérios é Doutor em Antropologia Social pelo Museu Nacional, Universidade Federal do Rio de Janeiro (UFRJ) e Professor Associado da Universidade Federal do Paraná (UFPR).

\section{REFERÊNCIAS}

Allouch, J. (1997). Érotique du deuil au temps de la mort sèche. Paris: Epel.

Bergé, C. (1990). La Voix des esprits. Ethnologie du spiritisme. Paris: Métailié.

Berl, E. (1995) [1956]. Présence des morts. Paris: Gallimard.

Bloch, M. (1993). La mort et la conception de la personne. Terrain, 20, 7-20. https://doi. org/10.4000/terrain.3055

Boyer, P. (2016). Pourquoi ne pas laisser les morts tranquilles ? Personnes contre-intuitives. In: A. Gros de Beler (ed). Persona.Étrangement humain (pp. 55-57). Paris: Musée du quai Branly; Arles: Actes Sud. 
Charuty, G. (2002) “Ça passe très vite et je n’y peux rien” : séances médiumniques dans une salle de voyance parisienne. Vacarme, 20(3), 73-74. https://doi.org/10.3917/vaca.020.0073

Damian, J. (2014). Intériorités/sensations/consciences. Sociologie des expérimentations somatiques du Contact-Improvisation et du Body-Mind Centering (Thèse de Doctorat). Université de Grenoble-École Doctorale Shpt, Grenoble.

Delaplace, G. (2015). Incertitudes morales, régimes de visibilités et vitesse de circulation des morts. In: G. Delaplace \& F. Valentin (eds). Le Funéraire. Mémoires, protocoles, monuments (pp. 11-23). Paris: De Boccard.

Esquerre, A. (2011). Les morts mobiles: étude sur la circulation des cendres en France. Raisons politiques, 41(1), 69-85. https://doi.org/10.3917/rai.041.0069

Favret-Saada, J. (2009). Désorceler. Paris: L'Olivier.

Féry, B. (2018). La Veuve du procureur. Paris: Persée.

James,W. (1913) [1909]. L'Idée de vérite. Paris: Félix Alcan.

James, W. (1948) [1911] Some Problems of Philosophy. A Beginning of an Introduction to Philosophy. New York: Longmans, Green, \& Co.

Kwon, H. (2008). Ghosts of War in Vietnam. Cambridge: Cambridge University Press. https://doi. org/10.1017/CBO9780511807596

Memmi, D. (2014). La Revanche de la chair. Essai sur les nouveaux supports de l'identité. Paris: Le Seuil.

Michelet, A. \& Stépanoff, C. (2016). Comment l'anthropomorphisme nous a rendus humains : l'anthropomorphisation des animaux et des nourissons et ses impacts dans l'évolution. In: A. Gros de Beler (ed). Persona. Étrangement humain (pp. 45-50). Paris: Musée du quai Branly; Arles: Actes Sud. Molinié, M. (2006). Soigner les morts pour guérir les vivants. Paris: Les Empêcheurs de penser en rond.

Pons, C. (2002). Le Spectre et le voyant. Les échanges entre morts et vivants en Islande. Paris: Presses de l'Université de Paris-Sorbonne.

Sorrentino, P. (2018). À l'épreuve de la possession. Chronique d'une innovation rituelle dans le Vietnam contemporain. Nanterre: Société d'ethnologie.

Souriau, É. (1939). L'Instauration philosophique. Paris: Félix Alcan 
Stengers, I. (2003). Cosmopolitiques, 2. Mécanique quantique, Au nom de la flèche du temps, La vie et l'artifice, Pour en finir avec la tolérance. Paris: La Découverte.

Stengers, I. (2006). La Vierge et le neutrino. Les scientifiques dans la tourmente. Paris: Les Empêcheurs de penser en rond.

Stengers, I. (2007). Préface. In: T. Nathan, Nous ne sommes pas seuls au monde. Les enjeux de l'ethnopsychiatrie. Paris, Le Seuil.

Stengers, I. (2014). Penser à partir du ravage écologique. In: É. Hache (ed). De l'univers clos au monde infini (pp. 147-190). Bellevaux: Dehors.

Viveiros de Castro, E. (2008). Claude Lévi-Strauss, CEuvres. Gradhiva, 8, 130-135. https://doi. org/10.4000/gradhiva.1215

Viveiros de Castro, E. (2009). Métaphysiques cannibales. Lignes d'anthropologie post-structurale. Paris: Presses universitaires de France. https://doi.org/10.3917/puf.castro.2009.01

Winter, Jay. (2008) [1995]. Entre deuil et mémoire. La Grande guerre dans l'histoire culturelle de l'Europe. Paris: Armand Colin. 


\section{PESQUISAR JUNTO AOS MORTOS}

Resumo: "Os mortos são gente como os outros". A partir dessa proposição, feita por um de seus interlocutores em campo, a autora se lança numa investigação sobre os dispositivos e agenciamentos que permitem reduzir distâncias entre vivos e mortos e operar a comunicação entre eles. Respeitando as indeterminações aí presentes, incorporando-as à descrição e restituindo a riqueza das operações engendradas pelos atores, inclusive seus próprios modos de investigar o significado das mensagens dos mortos/espíritos, o texto aborda uma variedade de temas que animam o debate antropológico, tais como: antropomorfismo, rituais de possessão, comunicação inteligível e sensível, regimes de verdade, dispositivos terapêuticos, entre outros.

Palavras-chave: Médium; Espiritismo; Morte; Luto.

\section{INQUIRIES RAISED BY THE DEAD}

Abstract: "The dead are people like everybody else". Beginning with this statement, made by one of the author's interlocutors, she launches an investigation into the devices and agencies that allow to reduce distances between alive and dead, searching the ways in which they establish communication. Respecting the indeterminations present therein and adding them in the description, the author depicts the diversity of the work engendered by the actors, including their own ways of inquiring the meaning of dead's / spirits' messages. The text addresses a variety of themes at the core of anthropological debates, such as: anthropomorphism, rituals of possession, intelligible and sensitive communication, régimes de vérité, therapeutic devices, among others.

Keywords: Medium; Spiritism; Death; Mourning.

RECEBIDO: $17 / 02 / 2021$

APROVADO: $10 / 04 / 2021$ 